\title{
Prevalence and factors associated with re-laparotomy among patients operated in Debre-Markos Referral Hospital, North West Ethiopia: Retrospective cross- sectional study
}

Nurhusien Nuru Yesuf ( $\nabla$ nuradisnuru@yahoo.com )

university of gondar https://orcid.org/0000-0002-5431-8212

Yeneabat Birhanu Yohanes

University of Gondar

Debrework Tesgera Bashah

University of Gondar

Tarkie Abebe Walle

University of Gondar

Henok Biresaw Netsere

university of gondar

Research article

Keywords: Re- laparotomy, first surgery, emergency surgery

Posted Date: August 30th, 2019

DOI: https://doi.org/10.21203/rs.2.11857/v1

License: (c) (i) This work is licensed under a Creative Commons Attribution 4.0 International License. Read Full License 


\section{Abstract}

Background Re-laparotomy is one of the causes of morbidity and mortality among patients with abdominal surgery; unless efforts are made to prevent in advance by identifying the potential risk factors.

Methods Retrospective cross-sectional study was conducted at Debre-Markos Referral Hospital from three hundred and ninety charts (390) from January 1, 2015, to January 30, 2017. Data were analyzed using Statistical Package for Social Science (SPSS) version 22. The associated factors for re-laparotomy were identified using multivariable logistic regression. P-value $<0.05$ was considered to be statistically significant.

Results We studied 390 patients based on charts. Two hundred seventy-four patients (70.3\%) were males. Forty-eight patients (12.3\%) performed re-laparotomy. Patients with the duration of operating on initial surgery $>60 \mathrm{hrs,}$ $\mathrm{AOR}=3.30(95 \% \mathrm{Cl}[1.40-7.41, \mathrm{p}=0.05])$, diabetes mellitus, $\mathrm{AOR}=4.79(95 \% \mathrm{Cl}[1.55-14.80, \mathrm{p}=0.007])$, elective surgery, $\mathrm{AOR}=0.17(95 \% \mathrm{Cl}[0.05-0.56, \mathrm{p}=0.004])$

Conclusion Even re-laparotomy is preventive; it is found to be in-patients underwent abdominal surgery. Therefore, appropriate preventive intervention to be taken to change those factors of the first surgery.

\section{Background}

Re-laparotomy defined as a re-abdominal operation performed within 60 days relate to the first surgery (1). Re-laparotomy reported in different parts of the world, which accounts about $1.5-27 \%$ of patients with abdominal surgery (1-7).

Re-laparotomy occurs once or more than once related to complications (8). It is one of the causes of morbidity and mortality among patients with abdominal surgery $(1,9)$; unless efforts are made to prevent in advance by identifying the potential risk factors. The most common indications for relaparotomy are peritonitis, infection, bleeding, abscess, anastomotic leakage, wound dehiscence, necrotizing pancreatitis, bowel necrosis, bowel obstruction and evisceration $(10,11)$. This study concluded that patients with re-laparotomy had high in mortality as well as exposed to the disease $(10,11)$. Research, however, lacks in examining the effect of re-laparotomy on abdominal surgical patients. It suggested that patients with re-laparotomy are at higher risk of morbidity and mortality (2). This higher often attributed to treatment of complications take a long time, which creates a psychological and economic burden of those who are undergoing repeated abdominal surgery related to the first abdominal surgery of mortality (12). Repeated abdominal surgery can induce the patient a poorer immunity resistance (13), which may influence postoperative outcomes. Even Preoperative and postoperative antibiotic, counting of the instruments, instrumental processing and wound care (14) used as a preventive approach; problems of health system service, patient factors (15), and comorbidity (9) may be underlying factors leading to poorer outcomes after first surgery. Although it is preventable, it is still one of the problems after first surgery. Most of the problems occur to individual particularly general surgery (16).

Re-laparotomy is one of the conditions associated with providing inappropriate health services at first surgery for which prevention is possible with proper intervention (3,13, 17-19). In an individual with abdominal surgery, the presence of re-laparotomy may affect in many ways. It contributes to lengthening the hospital stay, then to the high chance of mortality $(12,13)$. Most individuals with re- 
abdominal opening worldwide are urgently or latently develop complications, mortality rate considerably high (2).

The management of people with re-laparotomy is challenging because of more complications leads the client to multi-organ failure $(1,9,13,18)$. I think patients and health workers need positive outcome of first surgery. However, re-laparotomy occurred in the different part of the world. Information on the magnitude and associated factors of re-laparotomy is necessary to focus attention on minimizing the problem. Although the re-laparotomy expected in abdominal surgery, there is lack of evidence showing the magnitude of the problem and associated factors in Ethiopia.

Therefore, to offer baseline information and highlight magnitude of the problem, the current study was proposed to assess the prevalence and factors associated with re-laparotomy in Debre-Markos Referral Hospital.

\section{Methods}

\section{The study design and setup}

A retrospective cross-sectional study conducted at Debre-Markos Referral Hospital. Debre-Markos is $300 \mathrm{~km}$ from the capital city Addis Ababa. The hospital established was in 1964 and provide outpatient and inpatient services for more than 3.5 million peoples living in its catchment area.

\section{Source population}

All patients treated with laparotomy surgery in Debre-Markos Referral Hospital were source population.

\section{Study population}

Records of all patients that undergo laparotomy in Debre-Markos Referral Hospital from January 1, 2015, to January 30, 2017, were study population.

\section{Sample size determination}

The sample size determined by using single population proportion formula for the assumption of $50 \%$ proportions, $95 \%$ confidence level, and $5 \%$ margin of error. The total sample size was 384 charts. By assuming a $10 \%$ nonresponse rate, the last sample size determined as 422 . 


\section{Sampling technique}

Simple random sampling methods were applied for the choice of charts from 875 abdominal surgeries in general surgery by using the patient's medical registration number (MRN) following open EPI version 3.

\section{Data collection and rules}

After pretest was conducted $5 \%$ of charts from University of Gondar Referral Hospital, then real data was collected from Debre-Markos Referral Hospital. Primarily total two years laparotomy from January 2015 to January 2017 was counted. The list of patients with laparotomy procedure selected from the record books in the operating room. Followed by, medical registration numbered (MRN) of everyone recorded and then open EPI version 3 applied to 422 charts. By using card numbers, charts of the patient retrieved from the card room for collect variables.

\section{Variables of the study}

\section{Dependent variable}

Re-laparotomy

\section{Independent variables}

Age, Sex, operating room (OR) latency, type of procedure, urgency of surgery, Site of surgery, hypertension (HTN) , diabetes mellitus (DM) , hepatic malignancy, Chronic Obstructive Pulmonary Disease (COPD), Ischemia, peripheral vascular disease, jaundice $>3$ months, end stage of renal disease, Stricture behavior at diagnosis were independent variables.

\section{Operational definitions}

\section{Operating room latency}

Delays onset of the symptom of surgery $>60 \mathrm{hr}$

\section{Re-laparotomy}

It is re-operation of the abdominal surgery site associated with the first surgery within 60 days.

\section{Stricture behavior at diagnosis}

It is inflammatory bowel diseases, which involves small bowel stricture, colonic stricture and lead to significant complications.

\section{Index surgery}

It is the first time for the abdominal surgery. 


\section{Urgency}

Elective or emergency conditions condition of the surgery.

\section{Surgery site}

It is the site the surgical procedure.

\section{Data processing and analysis}

Data were coded and cleaned using EPI INFO version 7statistical software and exported to SPSS version 22 for analysis. Descriptive statistics were used to present socio-demographic, surgical interventions and co-morbidities. Percentages, frequencies, and cross tabulation were used to describe patient characteristics and surgical characteristics. Bi-variable and multivariable logistic regression model was used to identify associated factors of relaparotomy. The finding was presented using unadjusted and adjusted odds ratios and their $95 \%$ Confidence Intervals. The p-Value of less than 0.05 considered as statistically significant in multivariable analysis.

\section{Ethical considerations}

Ethical clearance obtained from the University of Gondar, College of Medicine and Health Science Ethical review board. A formal letter of cooperation was written to Debre-Markos Referral Hospital and obtained permission from Hospital management before starting data collection. After the purpose and aim of the study had informed, verbal consent obtained from the chart room workers. Data were kept anonymously in the distributed data extraction format to keep confidentiality.

\section{Results}

\section{Socio-demographic characteristics of participants}

A total of 422 charts retrieved for study. Among these, $116(29.7 \%)$ were females, and 274(70.3\%) were males with the age range of $7 y e a r s$ to 75 years. Of the 422 charts, 390(92\%) charts were found complete. Among 390 charts, relaparotomy identified from 48 patients with the prevalence of $12.3 \%$. Thirty-one (64.6\%) men and seventeen (35.4\%) women were undergoing re-laparotomy (table 1). About 48/390 (12.3\%) of the total re-laparotomy $14(3.6 \%)$, $13(3.3 \%), 11(2.8 \%), 9(2.3 \%), 1(0.3 \%)$ were belonged in age group of $46-60,31-45$, above $60,16-30$, and less than 16 years old respectively (Table 1 ).

\section{Prevalence of re-laparotomy relation to features surgical intervention on patients operated in general surgery.}

Lower gastrointestinal system surgeries such as colon 25(6.4\%), and appendix $14(3.6 \%)$ was leading procedure followed by gallbladder 2(0.5\%) (Table 2).

More than half of re-laparotomy performed following Operative Room latency > $60 \mathrm{hrs} 39(10.0 \%)$ and emergency surgery 44(11.3\%) (Table 2). 


\section{Co-morbidities}

Thirty-four patients (70.8\%) had one or more co-morbidities namely DM 13(3.3\%), hypertension 10(2.6\%) and Chronic obstructive pulmonary disease 11(2.8\%) ( Table 3).

\section{Factors associated with re-laparotomy}

On bi-variable logistic regression model, six variables; such as latency of first surgery $>60 \mathrm{hr}$, elective surgery, IEOS professionals, DM, HTN, and COPD were associated with re-laparotomy at $p<0.25$.

The latency of surgery greater than $60 \mathrm{hr}$, elective surgery and DM were independently associated factors of relaparotomy in multi-variable regression analysis.

Multivariable logistic regression analysis revealed patients with the duration of operating on initial surgery $>60 \mathrm{hrs}$ were 3.3 times more likely to develop re-laparotomy compared with patients underwent first abdominal surgery within $<60 \mathrm{hrs}$ of the illness, $\mathrm{AOR}=3.30(95 \% \mathrm{Cl}[1.40-7.41])$. Moreover, patients with diabetes mellitus were 4.8 times more likely to develop re-laparotomy compared patients who have no diabetes mellitus, $\mathrm{AOR}=4.79(95 \% \mathrm{Cl}[1.55-14.80])$. But patients with elective surgery were about $83 \%$ times less likely to undergo re-laparotomy compared those patients that had emergency abdominal surgery, AOR=0.17(95\% CI [0.05-0.56]) (Table 4). 


\section{Discussion}

Out of 390 patients who underwent laparotomy procedure, 48 patients performed re-laparotomy which gives the overall prevalence of $12.3 \%$. The finding was similar to studies done in USA $15 \%$ (3). The finding also supported by a study conducted in India 18.5\% (21). But, our finding was higher than compared to the study done in Zambia $3.3 \%$ (5). The discrepancy might be due to the inclusion of gynecological and obstetric surgery in those studies while only general surgery included in our study. Another discrepancy might be due to less study period, one year study period only conducted in those study while two year's study period in our study. But the finding was lower compared with the study conducted at Netherlands 27 \% (22). The studies done in the Netherlands included only emergency surgery but in our study, both emergency and elective surgeries included, this might be due to the reason why those studies find out high prevalence of re-laparotomy compared to our study.

The present study revealed that patients OR latency in $>60 \mathrm{hrs}$ were 3.3 times more likely develop re-laparotomy compared with patients operated in $<60 \mathrm{hrs}$ with $\mathrm{AOR}=3.30(95 \% \mathrm{Cl}[1.40-7.41$, P-value $=0.05])$. The study was in agreement with other studies (17) confirming that as the duration of illness goes up the risk occurrence of relaparotomy increases. Authors revealed that severity of illness increases to develop re-laparotomy due to perforation or generalized peritonitis (23).

We found that patients with elective surgery about $83 \%$ times less likely to develop re-abdominal operation compared with patients who conducted emergency surgery with $\mathrm{AOR}=0.17(95 \% \mathrm{Cl}[0.05-0.56, \mathrm{P}$-value $=0.004])$. This finding was in line with other studies done in Korea (6).

Authors revealed that, in elective surgery, there is time to plan and optimize the patient before the operation but in the emergency, it is striking (7).

In the present study, patients who had the history of DM were 4.8 times more likely to develop re-laparotomy, AOR=4.79 $(95 \% \mathrm{Cl}$ [1.55-14.80, P-value=0.007]) compared with patients who had no history of DM which is in line with another study (24), this might be due to the high level of blood sugar which makes a comfortable condition for the multiplication of micro-organisms and makes reopen of abdominal surgery. 


\section{Conclusions}

The overall prevalence of re-laparotomy was $12.3 \%$ which was higher compared with the report from some developing countries like Tanzania and lower compared to developed countries. OR latency in $>60 \mathrm{hrs}$, emergency surgery and DM were associated factors for re-laparotomy. Examining and identifying high-risk patients and accordingly taking all appropriate care should be done to decrease the risk of re-laparotomy. Shortening the preoperative hospital stay and duration operation further decrease the prevalence of re-laparotomy. Further researches with long study period and with large sample size should be done to get overall associated factors of re-laparotomy.

\section{Abbreviations}

COPD Chronic Obstructive Pulmonary Disease

DM Diabetic Mellitus

GIS Gastro-Intestinal System

HPB Hepatic-Pancreatic-Biliary

HTN Hypertension

IEOS Integrated Emergency obstetrics and Surgery

MRN Medical Registration Number

OR Operating Room 


\section{Declarations}

\section{Ethical considerations}

The ethical clearance was obtained from the ethical review committee of the department of surgical nursing on behalf of the Institutional Review Board of the University of Gondar. Permission letter was obtained from debermarkos town healthy office administration. Furthermore, after a thorough discussion and explanations of the purpose, benefit and the possible risks of the study, oral informed consent was obtained from each study participants. Women aged below 18 years would have allowed participating in the study considering that they are emancipated minors. The study participant's confidentiality was maintained by avoiding possible identifiers, such as the name of the client, and using only numerical identification.

\section{Authors' contributions}

WW conceived the research idea and prepared the proposal, participated in the data collection process, analyze data and draft the paper. NN and AD approved the proposal with some revisions, participated in the data analysis and reviewed the manuscript. All authors approved the final draft of the manuscript.

\section{Acknowledgments}

The authors would like to thank data collectors for their collaboration. We would also like to thank the University of Gondar for the ethical clearance.

\section{Competing Interests}

The authors have declared that they have no competing interests.

\section{Availability of Data and Materials}

All necessary data are available in the manuscript if electronics data are requested to submit, it will be done through the corresponding author.

\section{Funding Organization}

The University of Gondar which funded the project has no role in the process of the research work.

\section{Authors' detail}

${ }^{1}$ YB is Lecturer, Department of surgical Nursing, College of Medicine and Health Sciences at the University Of Gondar, Ethiopia. YB has a Bachelor of Science Degree in Nursing and Master's Degree 
in surgical nursing.

${ }^{2}$ NN Lecturer, Department of Surgical Nursing, College of Medicine and Health Sciences at the University of Gondar, Ethiopia. NN has Bachelor of Science Degree in Nursing and Master's Degree in Surgical Nursing.

${ }^{3} \mathrm{AD}$ is Lecturer, Department, Department of Emergency and Critical Nursing, College of Medicine and Health Sciences at the University of Gondar,Ethiopia. AD has Bachelor of Science Degree in Nursing, MSc in Emergency and Critical Nursing.

\section{Declaration}

This declaration statement is to verify that all authors have agreed on the manuscript to being submitted and no any disagreement of concern to declaring. We confirm that; the article is the original work of authors, and the data that support the findings of this study are available from the corresponding author. We affirm that the article has not received earlier publication and is not under consideration for publication elsewhere. We have ensured that the submission made here, including the main paper, database entries, and software code, does not contain any plagiarized material. We attest to the fact that all authors listed here have contributed notably to the effort, have read the manuscript, attest to the validity and legitimacy of the data and its interpretation, and agree to its submission of the BioMed central nursing journal.

All authors agree that author list is correct in its content and order and that no revision of the author listed made without the official approval of the Managing Editor. No other authors will be added post submission unless editors receive the agreement to all authors and detailed information supplied about to why the author list should be amended. We agree to follow the formalities as given on the website of the journal.

As the corresponding author, I also declare that this work supported by the University of Gondar, Ethiopia.

I am submitting this on behalf of all authors.

\section{Acknowledgment}

Our exceptional gratitude goes to Debre-Markos Referral Hospital for providing us the necessary information and facilitating conditions while we were carrying out this study. We thank sr. Zintalem Yirga and sr. Aynaddis Wasie for their help during the work and the rest of our friends who devoted their precious time helping us in every aspect of our work. We are indebted to all chart room workers that have helped us in selecting charts until bringing to an end the work. We would like to express our gratefulness to the staff of Nursing, for their help in searching relevant references and helping us during our work. Finally, we would like to express our gratitude in advance to the department of nursing at Gondar University for providing the opportunity to do this research. 


\section{References}

1. Unalp HR, Kamer E, Kar H, Bal A, Peskersoy M, Onal MA. Urgent abdominal re-exploration. World Journal of Emergency Surgery. 2006;1(1):10.

2. Koirala R, Shakya V, Khanna S, Adhikary S, Agrawal C. Redo-laparotomies: reasons, morbidity, and outcome. Nepal Med Coll J. 2012;14(2):107-10.

3. Sutherland DE, Radosevich DM, Bellin MD, Hering BJ, Beilman GJ, Dunn TB, et al. Total pancreatectomy and islet autotransplantation for chronic pancreatitis. Journal of the American College of Surgeons. 2012;214(4):409-24.

4. Roy A. A Study To Find Out The Different Causes of Reexploration of Emergency Exploratory Laparotomy Cases in A Tertiary Care Hospital in Eastern India-A Two Years Experience. Global Journal Of Research Analysis. 2016;5(7).

5. <Dr.Mzaza A. A one year study of re-laparotomy at the University of teaching hospital, Lusaka, 2012.PDF>.

6. Lee KY, Yu CS, Lee KY, Cho YB, Park KJ, Choi G-S, et al. Risk factors of repeat abdominal surgery in Korean patients with Crohn's disease: a multi-center study of a Korean inflammatory bowel disease study group. Journal of the Korean Society of Coloproctology. 2012;28(4):188-94.

7. Saunders D, Murray D, Pichel A, Varley S, Peden C. Variations in mortality after emergency laparotomy: the first report on the UK Emergency Laparotomy Network. BJA: British Journal of Anaesthesia. 2012;109(3):368-75.

8. Fry D. Abdominal wall considerations in re-operative surgery. 2001.

9. Scriba MF, Laing GL, Bruce JL, Clarke DL. Repeat laparotomy in a developing world tertiary level surgical service. The American Journal of Surgery. 2015;210(4):755-8.

10. Martínez-Casas I, Sancho JJ, Ave E, Pons M-J, Membrilla E, Grande L. Preoperative risks factors of mortality after re-laparotomy: analysis of 254 patients. Langenbeck's Archives of Surgery. 2010;395(5):527-34.

11. Ching S, Muralikrishnan V, Whiteley G. Relaparotomy: a five-year review of indications and outcome. International journal of clinical practice. 2003;57(4):333-7.

12. Thombarapu U, Kodey PD, Koneru G. Retrospective studies of re-laparotomy in the department of obstetrics, gynecology and family planning in, rural tertiary care hospital, Andhra Pradesh, India. International Journal of Medical Research \& Health Sciences. 2015;4(3):582-6.

13. Koirala R, Mehta N, Varma V, Kapoor S, Kumaran V, Nundy S. Urgent Redo-Laparotomies: Patterns and Outcome-A Single Centre Experience. Indian Journal of Surgery. 2015;77(3):195-9.

14. Safety WP, Organization WH. WHO guidelines on safe surgery: 2009: safe surgery saves lives. 2009.

15. Vrancken Peeters M-P, Vrancken Peeters M-J, Corion LU, Breslau PJ. Quality control of colorectal surgery with an extensive complication registration system. Digestive surgery. 2005;22(3):168-73. 
16. Lamme B, Boermeester M, Reitsma J, Mahler C, Obertop H, Gouma D. Meta-analysis of relaparotomy for secondary peritonitis. British Journal of Surgery. 2002;89(12):1516-24.

17. Wakefield CH, Fearon KC. Laparotomy for abdominal sepsis in the critically ill. 2001.

18. Koperna T, Schulz F. Relaparotomy in peritonitis: prognosis and treatment of patients with persisting intraabdominal infection. World journal of surgery. 2000;24(1):32-7.

19. Moran B. Decision-making and technical factors account for the learning curve in complex surgery. Journal of Public Health. 2006;28(4):375-8.

20. Commission FDRoEPC. Summary and Statistical report of the 2007 population and housing census. Addis Ababa, Ethiopia. 2008.

21. Reddy J, Saxena R, Singh R, Pottakkat B, Prakash A, Behari A, et al. Reoperation following pancreaticoduodenectomy. International journal of surgical oncology. 2012;2012.

22. Strike C, Stommel MW, Schipper LJ, van Goor H, ten Broek RP. Risk factors for future repeat abdominal surgery. Langenbeck's Archives of Surgery. 2016;401(6):829-37.

23. Sartelli M, Catena F, Abu-Zidan FM, Ansaloni L, Biffl WL, Boermeester MA, et al. Management of intra-abdominal infections: recommendations by the WSES 2016 consensus conference. World Journal of Emergency Surgery. 2017;12(1):22.

24. Han Y, Kwon T-W, Ko G-Y, Park H, Choi JY, Cho Y-P. Clinical outcome of early re-laparotomy after elective open repair of abdominal aortic aneurysms. Annals of surgical treatment and research. 2015;88(3):160-5.

\section{Tables}

\section{Table1: Socio-demographic characteristics of surgical patients with laparotomy at Debre-Markos referral hospital, Northwest Ethiopia, from January 1, 2015, to January $30,2017$.}




\begin{tabular}{lll} 
Variables & \multicolumn{2}{l}{ Re-laparotomy } \\
\hline Age in year & Yes & No \\
<16yrs old & $1(0.3 \%)$ & $29(7.4 \%)$ \\
16-30yrs old & $11(2.8 \%)$ & $133(34.1 \%)$ \\
31-45yrs old & $13(3.3 \%)$ & $72(18.5 \%)$ \\
46-60yrs old & $14(3.6 \%)$ & $74(19.0 \%)$ \\
Above 60yrs & $9(2.3 \%)$ & $34(8.7 \%)$ \\
Sex & & \\
Female & $17(4.4 \%)$ & $99(25.4 \%)$ \\
Male & $31(7.9 \%)$ & $243(62.3 \%)$ \\
Residence & & \\
Urban & $19(4.9 \%)$ & $134(34.4 \%)$ \\
Rural & $29(7.4 \%)$ & $208(53.3 \%)$ \\
\hline
\end{tabular}

Table2. Frequency distribution of re-laparotomy in relation to features on surgical interventions in surgical patients at Debre-Markos Referral Hospital from January 1, 2015, to January 30, 2017. 


\begin{tabular}{|c|c|c|c|}
\hline \multicolumn{2}{|l|}{ Surgical intervention features } & \multicolumn{2}{|c|}{ Re-laparotomy } \\
\hline Lower GIS & & Yes & No \\
\hline \multirow[t]{2}{*}{ Colon } & Yes & $25(6.4 \%)$ & $91(23.3 \%)$ \\
\hline & No & $23(5.9 \%)$ & $251(64.4)$ \\
\hline \multirow{2}{*}{ Small intestine } & Yes & $4(1.0 \%)$ & $55(14.1 \%) \mathrm{s}$ \\
\hline & No & $44(11.3 \%)$ & 287(73.6) \\
\hline \multirow[t]{2}{*}{ Appendix } & Yes & $14(3.6 \%)$ & $146(37.4 \%)$ \\
\hline & No & $34(8.7 \%)$ & $196(50.3 \%)$ \\
\hline \multicolumn{4}{|l|}{ Upper GIS } \\
\hline \multirow{2}{*}{ Stomach } & Yes & $1(0.3 \%$ & $6(1.5 \%)$ \\
\hline & No & $47(12.3 \%)$ & $336(86.2 \%)$ \\
\hline \multicolumn{4}{|l|}{ HPB system } \\
\hline \multirow{2}{*}{ Gall bladder } & Yes & $2(0.5 \%)$ & $12(3.1 \%) \mathrm{s}$ \\
\hline & No & $46(11.8 \%)$ & $330(84.6 \%)$ \\
\hline \multirow[t]{2}{*}{ Abdominal wall } & Yes & $1(0.3 \%)$ & $22(5.7 \%)$ \\
\hline & No & $47(12.0 \%)$ & $320(82.0 \%)$ \\
\hline \multirow[t]{2}{*}{ Initial surgery site other } & Yes & $1(0.3 \%)$ & $10(2.6 \%)$ \\
\hline & No & $47(12.0 \%)$ & $332(85.1 \%)$ \\
\hline \multirow[t]{2}{*}{ Other initial surgery procedure } & Yes & $1(0.3 \%)$ & $12(3.0 \%)$ \\
\hline & No & $47(12.0 \%)$ & $330(84.7 \%)$ \\
\hline \multirow[t]{2}{*}{ The latency of initial surgery } & $>60 \mathrm{hrs}$ & $39(10.0 \%)$ & $182(46.7 \%)$ \\
\hline & $<60 h r s$ & $9(2.3 \%)$ & $160(41.0 \%)$ \\
\hline \multirow[t]{2}{*}{ The urgency of initial surgery } & Emergency & $44(11.3 \%)$ & $261(66.9 \%)$ \\
\hline & Elective & $4(1.0 \%)$ & $81(20.8 \%)$ \\
\hline \multirow[t]{3}{*}{ Professional who perform the initial surgery } & Surgeon & $12(3.0 \%)$ & $141(36.2 \%)$ \\
\hline & IEOS & $16(4.1 \%)$ & 115(29.5\%) \\
\hline & Both & $20(5.2 \%)$ & $86(22.0 \%) \mathrm{s}$ \\
\hline
\end{tabular}

Another surgery site* prostate gland

Table3. Re-laparotomy following co-morbidities in surgical patients at Debre-Markos Referral Hospital from January 1, 2015, to January 30, 2017. 


\begin{tabular}{|c|c|c|c|}
\hline \multirow[t]{2}{*}{ Comorbidities } & & \multicolumn{2}{|c|}{ Re-laparotomy } \\
\hline & & Yes & No \\
\hline \multirow[t]{2}{*}{ Diabetes mellitus } & Yes & $13(3.3 \%)$ & $10(2.6 \%) \mathrm{s}$ \\
\hline & No & $35(9.0 \%)$ & $332(85.1 \%)$ \\
\hline \multirow[t]{2}{*}{ Hypertension } & Yes & $10(2.6 \%)$ & $6(1.5 \%)$ \\
\hline & No & $38(9.7 \%)$ & $336(86.2 \%)$ \\
\hline \multirow[t]{2}{*}{ Chronic obstructive pulmonary disease } & Yes & $11(2.8 \%)$ & $13(3.3 \%) \mathrm{s}$ \\
\hline & No & $37(9.5 \%)$ & $329(84.4 \%)$ \\
\hline \multirow[t]{2}{*}{ >3months jaundice } & Yes & $1(0.3 \%)$ & $6(1.5 \%)$ \\
\hline & No & $47(12.0 \%)$ & $336(86.2)$ \\
\hline \multirow[t]{2}{*}{ Hepatic malignancy } & Yes & $1(0.3 \%)$ & $2(0.5 \%)$ \\
\hline & No & $47(12.0 \%)$ & $340(87.2 \%)$ \\
\hline \multirow[t]{2}{*}{ Peripheral vascular diseases } & Yes & $3(0.8 \%)$ & $5(1.3 \%) \mathrm{s}$ \\
\hline & No & $45(11.5 \%)$ & $337(86.4 \%)$ \\
\hline
\end{tabular}

Table4. Bivariable and Multivariable regression analysis of factors associated with relaparotomy among patients operated at Debre-Markos referral hospital, DebreMarkos, Northwest Ethiopia, January 01-2015 to January 30-2017 


\begin{tabular}{|c|c|c|c|c|c|c|}
\hline \multirow[t]{2}{*}{ Variables } & & \multicolumn{2}{|c|}{ Re-laparotomy } & \multirow[t]{2}{*}{ COR(95\%CI) } & \multirow[t]{2}{*}{ AOR(95\%CI) } & \multirow{2}{*}{$\begin{array}{l}\mathrm{P} \text { - } \\
\text { value }\end{array}$} \\
\hline & & Yes & No & & & \\
\hline \multirow{2}{*}{$\begin{array}{l}\text { The latency } \\
\text { of initial } \\
\text { surgery }\end{array}$} & $>60 \mathrm{hrs}$ & $39(10.0 \%)$ & $182(46.7 \%)$ & $3.81(1.80,8.10)$ & $3.3(1.40,7.41)$ & $0.05 *$ \\
\hline & $<60 \mathrm{hrs}$ & $9(2.3 \%)$ & $160(41.0 \%)$ & 1 & & \\
\hline \multirow[t]{2}{*}{ Urgency } & Elective & $4(1.0 \%)$ & $81(20.8 \%)$ & $0.29(0.10,0.84)$ & $0.17(0.05,0.56)$ & $0.004^{*}$ \\
\hline & Emergency & $44(11.3 \%)$ & $261(66.9 \%)$ & 1 & & \\
\hline $\begin{array}{l}\text { Professional } \\
\text { who }\end{array}$ & Surgeon & $141(36.5 \%)$ & $12(3.08 \%)$ & 1 & & \\
\hline \multirow{2}{*}{$\begin{array}{l}\text { perform the } \\
\text { initial } \\
\text { surgery }\end{array}$} & IEOS & $115(29.5 \%)$ & $16(4.1 \%)$ & $1.64(0.75,3.60)$ & $1.05(0.43,2.55)$ & 0.9 \\
\hline & Both & $86(22.05 \%)$ & $20(5.13 \%)$ & $2.73(1.28,5.89)$ & $1.80(0.85,4.27)$ & 0.20 \\
\hline \multirow[t]{2}{*}{ DM } & Yes & $13(3.3 \%)$ & $10(2.6 \%)$ & $12.33(5.03,30.18)$ & $4.79(1.55,14.80)$ & $0.007 *$ \\
\hline & No & $35(9.0 \%)$ & $332(85.1 \%)$ & 1 & & \\
\hline \multirow[t]{2}{*}{ HTN } & Yes & $10(2.6 \%)$ & $6(1.5 \%)$ & $14.73(5.07,42.80)$ & $4.74(0.95,23.69)$ & 0.06 \\
\hline & No & $38(9.7 \%)$ & $336(86.2 \%)$ & 1 & & \\
\hline \multirow[t]{2}{*}{ COPD } & Yes & $11(2.8 \%)$ & $13(3.3 \%)$ & $7.52(3.16,17.99)$ & $2.30(0.73,7.30)$ & 0.16 \\
\hline & No & $37(9.5 \%)$ & $329(84.4 \%)$ & 1 & & \\
\hline
\end{tabular}

\section{P-value $\leq 0.05 *$}

